\title{
Human sperm characteristics during frequent ejaculation*
}

\author{
Nan B. Oldereid, J. O. Gordeladze, B. Kirkhus and K. Purvis \\ Institute of Pathology, The National Hospital, Oslo, Norway
}

\begin{abstract}
Summary. Sperm concentration, morphology, DNA condensation and nuclear protein pattern as well as sperm adenylate cyclase were evaluated in semen samples provided by 7 volunteers every $8 \mathrm{~h}$ for 2 days. During the observation period, sperm concentration and total sperm number decreased but began to return towards normal after a 3day abstinence period. No increase in the proportion of immature sperm cells was observed by light microscopy. Total adenylate cyclase (EC 4.6.1.1) increased significantly per cell, due to an increase in the soluble component while the particulate component remained relatively constant. Microflow fluorometry revealed no consistent alterations in the DNA or nuclear protein distribution. We conclude that although a high frequency of ejaculation does not disturb the conventional measures of sperm integrity, such as DNA condensation, there are major changes in at least one biochemical measurement, the activity of soluble adenylate cyclase.
\end{abstract}

\section{Introduction}

Several functions have been attributed to the mammalian epididymis. It acts as a sperm reservoir, produces the epididymal plasma, promotes the maturation of spermatozoa, and aids in the disposal of ageing and superfluous spermatozoa (see review by Bedford, 1975). The importance of transit time through the epididymis for these processes has never been fully evaluated. In man, data obtained with ${ }^{3} \mathrm{H}$-labelled thymidine suggests a mean transit time of approximately 12 days (Bedford, 1975). The alterations which occur in the spermatozoon during epididymal transit are numerous and include the acquisition of fertilizing ability, the development of full motility, migration of the cytoplasmic droplet, reduction in the amount of cytoplasm, alterations in the size, shape and contents of cell organelles (Mann \& Lutwak-Mann, 1981), changes in the degree of DNAcompaction (Kvist, 1980), increase in the activity of adenylate cyclase (EC 4.6.1.1) and protein carboxyl-methylase (Purvis, Cusan, Attramadal, Ege \& Hansson, 1982), and alterations in the sperm plasma membrane (Olson \& Danzo, 1981).

Only a few studies have been reported on the effects of repeated ejaculation on transit time or sperm characteristics in the human (Freund, 1962, 1963). These publications concentrated on sperm number and motility and did not monitor biochemical alterations.

The aim of the present study was to investigate the effects of a high ejaculation frequency in a group of human volunteers on certain characteristics of sperm function including sperm number, morphology, the DNA and nuclear chromatin pattern and adenylate cyclase activity. The latter enzyme has been implicated as a primary regulator of sperm motility (Gordeladze, Cusan, Åbyholm \& Hansson, 1982b).

\footnotetext{
* Reprint requests to: Dr K. Purvis.
} 


\section{Materials and Methods}

The semen specimens were provided by 7 young medical students, aged $20-28$ years. An abstinence period of 3 days preceded the first ejaculation. This first ejaculate is subsequently referred to as the control.

Semen specimens were received from each donor every $8 \mathrm{~h}$ for 2 days. After the 6 th ejaculation there was an abstinence period of another 3 days before the last semen sample. The specimens were collected at home by masturbation into a condom and transferred to tubes and frozen at $-20^{\circ} \mathrm{C}$. Motility and forward progression were not rated. The tubes were transferred to $-70^{\circ} \mathrm{C}$ when all samples were obtained from each donor. After thawing, the samples were allowed to liquefy for 10 min at room temperature. Thereafter seminal volume and sperm concentrations were measured.

After centrifugation at $1500 \mathrm{~g}$ for $10 \mathrm{~min}$, the sperm cells were then twice washed with saline $(9 \mathrm{~g}$ $\mathrm{NaCl} / \mathrm{l}$ ). Duplicate smears were made, fixed in methanol, stained with Giemsa, and examined under the light microscope. The abnormal cells were classified into 9 subgroups as described by Zaneveld \& Polakoski (1977): tapered head, macrocephalic, microcephalic, absent head, amorphous and double heads, tail abnormality, immature spermatozoon, and others. Spermatozoa were designated immature when they showed evidence of a cytoplasmic droplet but otherwise normal morphology.

DNA. The fixed cells were washed in saline and stained for DNA flow cytometry with a combination of the fluorochromes ethidium bromide and mitramycin (Barlogie et al., 1976). Fluorescence and forward light scatter were measured simultaneously in an Ortho Cytofluorograph $50 \mathrm{H}$ (Ortho Instruments, Westwood, MA, U.S.A.). An argon-laser was used at the wavelength $457.9 \mathrm{~nm}(120 \mathrm{~mW})$ for the excitation. Two-parameter analysis of fluorescence versus forward light scatter was performed to exclude clumps and debris from the DNA fluorescence distributions. From these distributions the percentage of haploid and diploid cells in each ejaculate could be readily calculated.

Adenylate cyclase. A detailed account of the procedure has been fully described elsewhere (Gordeladze et al., 1982b). The prewashed spermatozoa were suspended in $10 \mathrm{~mm}$-Tris-HCl buffer, pH $7 \cdot 5$, containing $1 \mathrm{mM}$-EDTA and $1 \mathrm{mM}-\beta$-mercaptoethanol and sonicated in an MSE $100-\mathrm{W}$ Ultrasonic Disintegrator for $10 \mathrm{sec}$ at amplitude setting 5. Membrane particles and cytosol were separated by centrifugation for $60 \mathrm{~min}$ at $27000 \mathrm{~g}$ and $4^{\circ} \mathrm{C}$. The membrane fraction was resuspended in the same buffer by repeated sonication for $5 \mathrm{sec}$. Samples $(20 \mu \mathrm{l})$ of the membrane suspension and cytosol were incubated at $35^{\circ} \mathrm{C}$ for $40 \mathrm{~min}$ in a final volume of $50 \mu \mathrm{l}$ comprising 1 mM-ATP (including $2.6 \times 10^{6}$ c.p.m. $\left[\gamma^{32} \mathrm{P}\right] \mathrm{ATP}$ (sp. act. $40 \mathrm{Ci} / \mathrm{mmol}$ )/tube), $1 \mathrm{mM}$-cAMP (including 7000 c.p.m. $\left[{ }^{3} \mathrm{H}\right] \mathrm{cAMP}$ (sp. act. $25 \mathrm{Ci} / \mathrm{mmol}$ )), $15 \mathrm{mM}-\mathrm{Mn}^{2+}, 1.4 \mathrm{~mm}-\mathrm{EDTA}$ and a regenerating system (myokinase, creatine kinase and creatine phosphate) for ATP. The reaction was terminated by adding $100 \mu \mathrm{l}$ of a $1 \%$ sodium dodecyl sulphate solution containing ATP and cAMP. After chromatography on Dowex X-50 and alumina oxide, the isolated cAMP was counted to a preset total c.p.m. of 10000 . Each assay tube contained cellular constituents from $2 \times 10^{5}$ spermatozoa and the reaction/chromatography blank never exceeded $15 \%$ of the incubated sperm samples.

Statistics. Results were analysed by two-way analysis of variance and $t$ test.

\section{Results}

Text-figure 1(a) reveals that total sperm count decreased markedly when there was a high frequency of ejaculation. A significant $(P<0.05)$ decrease had occurred even by $8 \mathrm{~h}$ after the first ejaculation but sperm count thereafter decreased relatively slowly. The lowest count (6th 


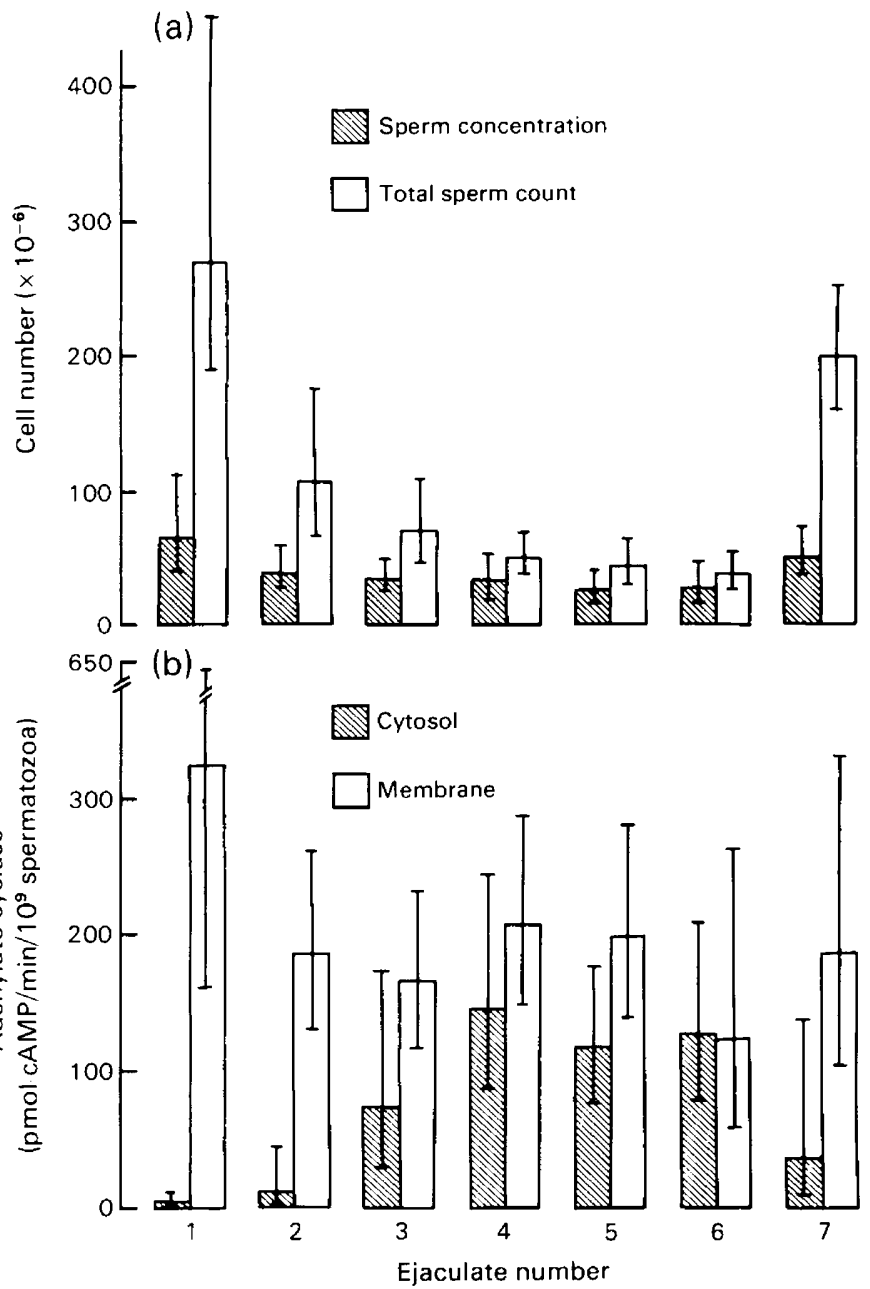

Text-fig. 1. Effect of a high ejaculation frequency in men on (a) sperm count and (b) adenylate cyclase activity in the cytosolic and membrane cellular compartments of spermatozoa. Data are expressed as geometric means (after logarithmic transformation), vertical bars represent $95 \%$ confidence limits. Ejaculates 1-6 were obtained every $8 \mathrm{~h}$. Ejaculate 7 was collected after a 3day abstinence period.

ejaculation) was $12 \%$ of the control value. Sperm concentration followed the same pattern but only decreased to about $40 \%$ of the control value.

After a 3-day abstinence period, control values had still not been restored. On this occasion the mean sperm concentration number was $71 \%$, and the total sperm number was $65 \%$ of the control sample (Text-fig. 1a). Corresponding sperm volumes (geometric means and $95 \%$ confidence limits) were $4 \cdot 8(3 \cdot 5-6 \cdot 5), 2 \cdot 7(1 \cdot 8-4 \cdot 0), 2 \cdot 0(1 \cdot 3-3 \cdot 0), 1 \cdot 5(1 \cdot 0-2 \cdot 2), 1 \cdot 8(1 \cdot 2-2 \cdot 3), 1 \cdot 4(0 \cdot 9-2 \cdot 1)$ and $4 \cdot 1 \mathrm{ml}$ $(2 \cdot 8-6 \cdot 5)$, respectively.

Light microscopy was used to classify cell morphology into normal and different abnormal forms. The relative distribution of these various forms within each individual did not alter with repeated ejaculations (Table 1). The proportion of immature spermatozoa also did not alter during the study. The high percentage of abnormalities, particularly tail anomalies, which can often appear after cold shock and centrifugation, may be due to the technical methods. 
Table 1. Effect of a high ejaculation frequency on the distribution of abnormal sperm cells in the ejaculates: results were pooled from 7 individuals at the same ejaculation number and expressed as mean percentage and range of the total number of cells in the ejaculates

\begin{tabular}{lccccccc}
\hline & \multicolumn{7}{c}{ Ejaculate number } \\
\cline { 2 - 8 } & 1 & 2 & 3 & 4 & 5 & 6 & 7 \\
\hline Tail abnormality & 27 & 27 & 31 & 32 & 30 & 29 & 32 \\
& $(16-44)$ & $(12-38)$ & $(7-54)$ & $(13-44)$ & $(11-45)$ & $(12-46)$ & $(17-47)$ \\
Tapered head & 2 & 1 & 0 & 1 & 1 & 1 & 1 \\
& $(0-4)$ & $(0-2)$ & $(0-1)$ & $(0-1)$ & $(0-1)$ & $(0-3)$ & $(0-2)$ \\
Microcephalic & 6 & 5 & 5 & 7 & 6 & 7 & 4 \\
& $(4-9)$ & $(1-7)$ & $(2-7)$ & $(1-15)$ & $(2-15)$ & $(2-12)$ & $(2-7)$ \\
Macrocephalic & 1 & 1 & 1 & 2 & 1 & 1 & 1 \\
& $(0-2)$ & $(0-1)$ & $(0-6)$ & $(0-4)$ & $(0-3)$ & $(0-3)$ & $(0-4)$ \\
Absent head & 5 & 5 & 4 & 4 & 4 & 4 & 4 \\
& $(1-8)$ & $(0-8)$ & $(0-7)$ & $(0-10)$ & $(0-7)$ & $(0-6)$ & $(0-8)$ \\
Amorphous head & 1 & 1 & 0 & 1 & 1 & 2 & 1 \\
& $(0-2)$ & $(0-2)$ & $(0-1)$ & $(0-2)$ & $(0-2)$ & $(0-3)$ & $(0-2)$ \\
Double head & 1 & 1 & 1 & 0 & 1 & 0 & 0 \\
& $(0-2)$ & $(0-1)$ & $(0-2)$ & $(0-1)$ & $(0-1)$ & $(0-1)$ & $(0-1)$ \\
Immature sperm & 4 & 4 & 3 & 4 & 4 & 1 & 2 \\
& $(0-5)$ & $(2-8)$ & $(1-7)$ & $(2-7)$ & $(2-7)$ & $(2-4)$ & $(1-5)$ \\
Other & 2 & 3 & 2 & 3 & 2 & 1 & 2 \\
& $(0-12)$ & $(0-11)$ & $(0-7)$ & $(0-7)$ & $(0-5)$ & $(0-3)$ & $(0-5)$ \\
\hline Total abnormal & 49 & 48 & 47 & 54 & 50 & 46 & 47 \\
\hline
\end{tabular}

As can be calculated from Text-fig. 1(b), the mean total adenylate cyclase increased by the 3rd ejaculation, reached a peak value at the 4 th ejaculation, and then subsequently decreased. After the abstinence period this value once again attained the control level. Cytosolic (soluble) adenylate cyclase was significantly increased above control levels by the 3rd ejaculation $(P<0.01)$, and stabilized at a high level after the 4th ejaculation $(P<0.001)$. After the abstinence period this pattern was reversed, but values still had not reached the initial value $(P<0.05$ compared to control). Membrane-bound adenylate cyclase remained relatively constant during the observation period.

The DNA distribution (Text-fig. 2) and nuclear chromatin pattern remained relatively constant during the ejaculation period. Generally there was no evidence of any systematic alterations in fluorochrome uptake by the germ cells, and no evidence of the appearance of subpopulations of germ cells with different fluorescence properties during the observation period.

\section{Discussion}

In confirmation of earlier reports (Freund, 1962, 1963), the present study shows that ejaculate volume and sperm number are markedly reduced during a period of high ejaculation frequency. Even at the time of the second ejaculation, $8 \mathrm{~h}$ after the first, total sperm counts were significantly lower than in the control ejaculate.

Sperm concentration remained relatively constant in all ejaculates, in contrast to a significant reduction in both volume and total sperm count, indicating that the sperm reserve may readily be depleted by an increase in emission frequency.

The morphology of the spermatozoa, as judged by light microscopy, did not appear to change during the observation period. This was further confirmed by the relative stability of the DNA and 


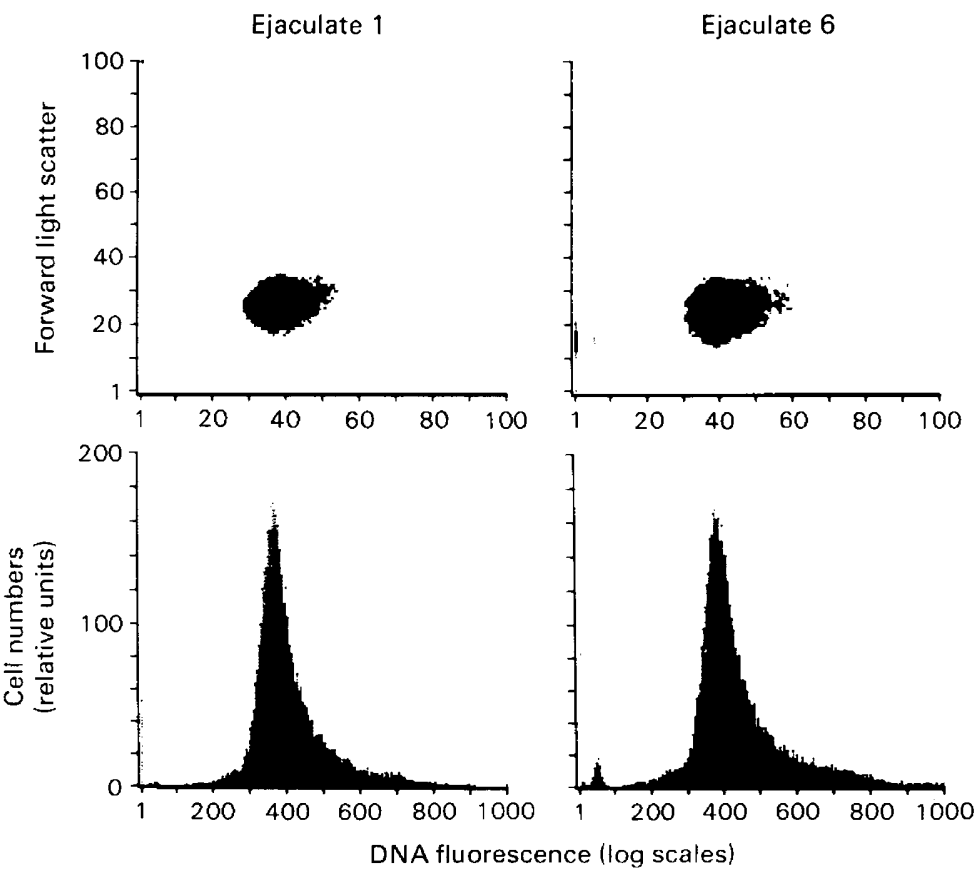

Text-fig. 2. Effect of a high ejaculation frequency in men on the DNA distribution in cells in Ejaculates 1 and 6 of one of the subjects.

protein pattern as indicated by microflow fluorometry. Previous investigations using this technique (Clausen, Kirkhus \& Abyholm, 1982) have shown that ejaculates of certain groups of infertile patients exhibit disturbances in DNA distribution.

Some of the volunteers showed great fluctuations in the percentages of haploid and diploid cells in the ejaculate and in the percentage of abnormal spermatozoa during the observation period. However, these changes did not follow a consistent pattern, and could not be related to the high ejaculation frequency. The results indicate that repeated ejaculations do not result in the appearance of immature germ cell forms, at least as judged from gross morphology.

Total adenylate cyclase appeared to increase by the 3rd ejaculation when measured per cell. However, this increase was due primarily to the activity of a soluble component. In the rat and human testis the early germ cells in the spermatogenic process are characterized by high levels of cytosolic adenylate cyclase and lower relative proportions of particulate enzyme (Gordeladze, Purvis, Clausen, Rommerts \& Hansson, 1981b; Gordeladze, Åbyholm, Cusan, Clausen \& Hansson, 1982a). Gordeladze, Andersen \& Hansson (1981a) have suggested that this cytosolic form represents an immature state of the particulate adenylate cyclase. Indeed, control spermatozoa in the present study and in previous studies (Gordeladze et al., 1982b) are characterized by a relatively high particulate adenylate cyclase activity. The fact that the particulate activity was not inversely related to the soluble activity suggests that one cannot simply account for this increased soluble enzyme by interference with transfer of the enzyme from one cellular compartment to another. The study indicates that, after repeated ejaculations, spermatozoa appear which are morphologically indistinguishable from normal sperm cells but which nevertheless exhibit differences in the content and location of the adenylate cyclase.

In the rat the relative activity of the soluble adenylate cyclase is low even in the caput epididymidis (Purvis et al., 1982), suggesting that conversion of the cytosolic to the particulate form occurs in the seminiferous tubules. Moreover, normal spermatids exhibit a much higher 
soluble/particulate ratio of cyclase activity than do the late elongated forms (Gordeladze et al., 1982a). It is therefore of great interest that, in the human, the cytosolic enzyme characteristic of the immature testicular germ cell appears so readily after repeated ejaculation.

The analysis of the accessory sex gland secretions from the same study is published elsewhere (Rui, Gerhardt, Mevåg, Thomassen \& Purvis, 1984) and reveals that the concentration of one of the components of seminal plasma, spermine, significantly increased after the 3 rd and 4 th ejaculations, apparently in parallel with the alteration in sperm adenylate cyclase reported in the present study. Spermine has been reported to activate human sperm adenylate cyclase (Shah, Sheth, Mugatwala \& Rao, 1975) although no information was provided regarding which cellular compartment was examined. An alternative explanation for the changes in sperm adenylate cyclase activity with repeated ejaculation may therefore be that it reflects exposure to alteration in the concentration of one of the components of the seminal plasma such as spermine. We are investigating the mechanisms underlying these changes.

This work was supported by Norsk Forening til Kreftens Bekjempelse. N.B.O. had a NAVF (Norwegian Research Council for Science and the Humanities) scholarship.

\section{References}

Barlogie, B., Spitzer, G., Hart, S., Johnston, D.A., Büchner, T., Schumann, J. \& Drewinko, B. (1976) DNA histogram analysis of human hemopoietic cells. Blood 48, 245-258.

Bedford, J.M. (1975) Maturation, transport and fate of spermatozoa in the epididymis. In Handbook of Physiology. Sect. 7, Endocrinology. Vol. 5, Male Reproductive System, pp. 303-317. Eds D. W. Hamilton \& R. O. Greep. American Physiological Society, Washington D.C.

Clausen, O.P.F., Kirkhus, B. \& Åbyholm, T. (1982) DNA flowcytometry of human ejaculates in the investigation of male infertility. Infertility 5, 71-85.

Freund, M. (1962) Interrelationship among the characteristics of human semen and factors affecting semen-specimen quality. J. Reprod. Fert. 4, 143-159.

Freund, M. (1963) Effect of frequency of emission on semen output and an estimate of daily sperm production in man. $J$. Reprod. Fert. 6, 269-286.

Gordeladze, J.O., Andersen, D. \& Hansson, V. (1981a) Physico-chemical and kinetic properties of the $\mathrm{Mn}^{2+}$-dependent adenylyl cyclase (AC) of the human testis. J. clin. Endocr. Metab. 53, 465-471.

Gordeladze, J.O., Purvis, K., Clausen, O.P.F., Rommerts, F.F.G. \& Hansson, V. (1981 b) Cellular localization of the $\mathrm{Mn}^{2+}$-dependent adenylyl cylcase $(\mathrm{AC})$ in rat testis. Int. J. Androl. 4, 172-182.

Gordeladze, J.O., Åbyholm, T., Cusan, L., Clausen, O.P.F. \& Hansson, V. (1982a) Cellular localization of the $\mathrm{Mn}^{2+}$-dependent adenylyl cyclase $(\mathrm{AC})$ in the human testis. Archs Androl. 8, 199-204.

Gordeladze, J.O., Cusan, L., Ảbyholm, T. \& Hansson, V. (1982b) Adenylyl cyclase (AC) and protein carboxyl methylase (PCM) in human ejaculated spermatozoa. Archs Androl. 8, 265-270.

Kvist, U. (1980) Sperm nuclear chromatin decondensation ability. Acta physiol. scand., Suppl. 486.

Mann, T. \& Lutwak-Mann, C. (1981) Male Reproductive Function and Semen, pp. 139-150. Springer-Verlag, Berlin.

Olson, G.E. \& Danzo, B.J. (1981) Surface changes in rat spermatozoa during epididymal transit. Biol. Reprod. 24, $431-443$.

Purvis, K., Cusan, L., Attramadal, H., Ege, A. \& Hansson, V. (1982) Rat sperm enzymes during epididymal transit. J. Reprod. Fert. 65, 381-387.

Rui, H., Gerhardt, P., Mevåg, B., Thomassen, Y. \& Purvis, K. (1984) Seminal plasma characteristics during frequent ejaculation. Int. J. Androl. (in press).

Shah, G.V., Sheth, A.R., Mugatwala, P.P. \& Rao, S.S. (1975) Effect of spermine on adenylyl cyclase activity of spermatozoa. Experientia 31, 631-632.

Zaneveld, L. \& Polakoski, L. (1977) Semen analysis. In Techniques of Human Andrology, pp. 469-480. Ed. E. S. E. Hafez. Elsevier/North-Holland Biomedical Press, Amsterdam.

Received 22 August 1983 